\title{
Late results of the Ross procedure
}

Tirone E. David, MD, Maral Ouzounian, MD, PhD, Carolyn M. David, BA, Myriam Lafreniere-Roula, PhD, and Cedric Manlhiot, PhD

\section{ABSTRACT}

Objective: The study objective was to examine the long-term results of the Ross procedure in a cohort of patients followed prospectively for more than 2 decades.

Methods: From 1990 to 2004, 212 consecutive patients with a median age (interquartile range) of 34 years (28-41) underwent the Ross procedure; $82 \%$ had congenital aortic valve disease. The technique of aortic root replacement was used in one half of the patients. Patients have been followed prospectively for a median (interquartile range) of 18.0 (14.6-21.2) years. Valve function was assessed by echocardiography.

Results: Cumulative mortality at 20 years was $10.8 \%$ (95\% confidence interval, 6.5-17.8). Thirty patients required Ross-related reoperations and 3 for coronary artery disease. The cumulative probability of Ross-related reoperations at 20 years was $16.8 \%$ (95\% confidence interval, 11.3-24.5), on the pulmonary autograft was $11.5 \%$ (95\% confidence interval, 7.2-18.0), and on the pulmonary homograft was $8.2 \%$ (4.6-14.7). The implantation technique was not associated with the cumulative incidence of reoperations on the pulmonary autograft. The development of moderate or severe aortic insufficiency and pulmonary homograft dysfunction increased with time. At 20 years, the probability of aortic insufficiency was $13 \%$ (95\% confidence interval, 8.0-20.3) and of pulmonary homograft dysfunction was $19.7 \%$ (95\% confidence interval, 13.9-27.2). Preoperative aortic insufficiency was associated with increased odds of postoperative aortic insufficiency.

Conclusions: The long-term results of the Ross procedure are excellent regardless of the implantation technique, but there is a progressive deterioration of function of both semilunar valves. (J Thorac Cardiovasc Surg 2019;157:201-8)

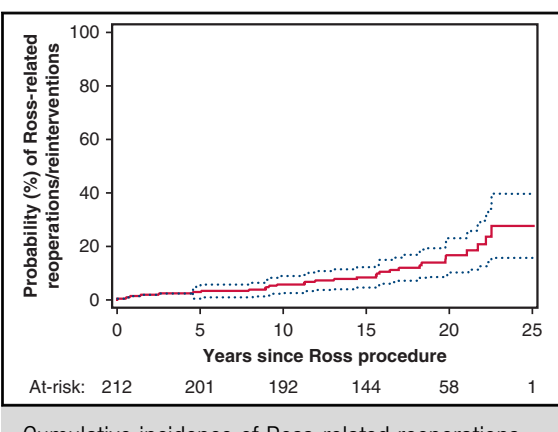

Cumulative incidence of Ross-related reoperations.

\section{Central Message}

The Ross procedure provides excellent longterm results, but there is a slow and progressive deterioration of function of both semilunar valves.

\section{Perspective}

The usefulness of the Ross procedure remains controversial, but numerous studies have demonstrated that it remains the best alternative to mechanical valves in young patients, particularly women during childbearing years and young men with aortic stenosis.

See Editorial Commentaries pages 209 and 211.

See Editorial page 199
The Ross procedure has been on and off the radar screen as an alternative to mechanical valves in young patients who need aortic valve replacement (AVR). ${ }^{1}$ As originally described, the pulmonary valve was sutured inside the aortic root in the subcoronary position and a semilunar valve homograft was used to replace the native pulmonary valve, a more demanding operation than AVR with a commercially available prosthetic heart valve. The realization that the

\footnotetext{
From the Division of Cardiovascular Surgery, Peter Munk Cardiac Centre, Toronto General Hospital and the University of Toronto, Toronto, Ontario, Canada.

Funded by the Academic Enrichment Fund of the Division of Cardiovascular Surgery at Peter Munk Cardiac Centre and a research grant from Miranda and Anthony Wong.

Received for publication March 1, 2018; revisions received May 23, 2018; accepted for publication June 3, 2018; available ahead of print Aug 10, 2018.

Address for reprints: Tirone E. David, MD, 200 Elizabeth St, 4N453, Toronto, Ontario M5G 2C4, Canada (E-mail: tirone.david@uhn.ca). $0022-5223 / \$ 36.00$

Copyright (c) 2018 by The American Association for Thoracic Surgery https://doi.org/10.1016/j.jtcvs.2018.06.037
}

Ross procedure could be performed by replacing the aortic root with the pulmonary root made it more attractive, and there was a renewed interest in the 1990s, but the enthusiasm faded when patients began to return with a dilated neoaortic root and aortic insufficiency (AI). ${ }^{2-4}$ The usefulness of the Ross procedure has remained controversial during the past 5 decades. We embraced it in 1990 and implanted the pulmonary autograft in the subcoronary position in patients whenever anatomically feasible and used the aortic root replacement technique when the anatomy of the coronary arteries or aortic root precluded proper alignment of the pulmonary autograft

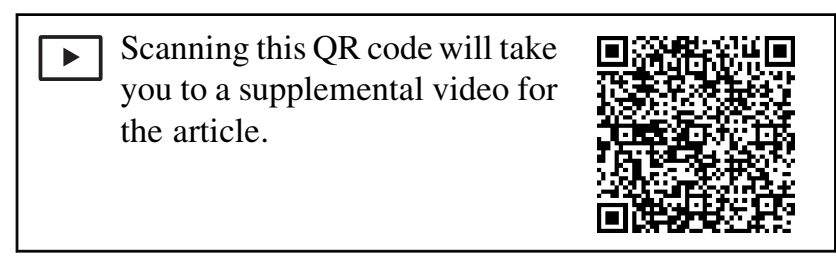




\section{Abbreviations and Acronyms \\ $\mathrm{AI}=$ aortic insufficiency \\ $\mathrm{AV}=$ aortic valve \\ $\mathrm{AVR}=$ aortic valve replacement \\ $\mathrm{CI}=$ confidence interval \\ $\mathrm{IQR}=$ interquartile range \\ PI = pulmonary insufficiency}

inside the native aortic root. The Ross procedure was offered to all healthy young patients who needed elective AVR from 1990 to 2004. This study is a progress report of our experience with the Ross procedure on a cohort of patients prospectively followed during the past 25 years.

\section{PATIENTS AND METHODS}

From January 1990 to December 2004, 212 consecutive patients underwent the Ross procedure at Toronto General Hospital. Two thirds of the patients were men, and the median (interquartile range [IQR]) age at surgery was 34 (28-41) years. All patients were followed prospectively by the referring cardiologist and contacted by our research personnel annually during the first 5 years and every 3 to 5 years thereafter. The median (IQR) follow-up was 18.0 (14.621.2) years. For this report, the follow-up was closed on December 31, 2017. Four patients could not be contacted during the last 3 to 5 years. Echocardiography was performed for assessment of valve function and to measure the diameters of the aortic root and ascending aorta. Approximately one third of all echocardiographic studies were done in outside institutions. If moderate or severe valve dysfunction was reported, the images were reviewed by our echocardiographers. We defined "pulmonary valve dysfunction" as moderate or severe pulmonary insufficiency (PI) or a peak systolic gradient $40 \mathrm{~mm} \mathrm{Hg}$ or greater. We have used these values to recommend reintervention if they are associated with symptoms or signs of right ventricular dilatation. A total of 1097 studies were available for analysis on 211 patients. Eight patients did not have any study during the most recent 5 years. The median (IQR) duration of echocardiographic follow-up was 16.4 (11.9-19.1) years. This study was approved by the Research Ethics Board of the University Health Network, and written consent was required after October 2016.

Table 1 shows the clinical profile and operative procedures in all patients. The pulmonary autograft was secured in the aortic position using the subcoronary implantation or aortic root inclusion techniques in 104 patients and as a freestanding neoaortic root in 108 patients. The decision to use one or the other technique was dictated by the aortic root pathology and the anatomy of the coronary arteries. Thus, in patients with a small aortic root, previous aortic valve (AV) surgery, or an anomalous right coronary artery (the orifice was too close to the aortic annulus or was displaced laterally or medially precluding proper alignment of the commissures of the autograft), the aortic root replacement technique was used. The diameters of the annulus and sinotubular junction of the pulmonary and aortic roots were measured with metric sizers during surgery and recorded. Because of the difficulty in measuring the diameter of the pulmonary annulus, it was estimated to be $15 \%$ to $20 \%$ larger than the diameter of the sinotubular junction of the pulmonary autograft. If the aortic annulus was larger than the pulmonary autograft annulus by more than 2 to $3 \mathrm{~mm}$, surgical adjustments were made before implanting the pulmonary autograft. ${ }^{3}$ The diameter of the sinotubular junction of the neoaortic root was also surgically adjusted to that of the pulmonary autograft.

\section{Statistical Analysis}

The primary outcomes of interest were mortality, reoperations, and the development of dysfunction of the aortic or pulmonary valves. Moderate or
TABLE 1. Clinical profile and operative procedures

\begin{tabular}{lc}
\hline \multicolumn{1}{c}{ Variables } & Result \\
\hline Age at surgery, median y (IQR) & $34(28-41)$ \\
$16-25$ & $38(17.9)$ \\
$26-35$ & $76(35.9)$ \\
$36-45$ & $70(33.0)$ \\
$46-63$ & $28(13.2)$ \\
Men & $140(66.0)$ \\
Year & \\
$<1994$ & $52(24.5)$ \\
$1995-1999$ & $95(44.8)$ \\
$2000-2004$ & $65(30.7)$ \\
Previous cardiac interventions & \\
Previous AV surgery & $30(14.2)$ \\
Previous mitral valve repair & $1(0.5)$ \\
Previous cardiac surgery (not listed above) & $12(5.7)$
\end{tabular}

Clinical presentation

Timing of surgery

Elective

$192(90.6)$

Same hospitalization

$20(9.4)$

Angina

39 (18.4)

Congestive heart failure

$34(16.0)$

Syncope

$19(9.0)$

NYHA functional class

I

$41(19.3)$

II

$135(63.7)$

III

$26(12.3)$

IV

$10(4.7)$

Left ventricular ejection fraction
$\geq 60 \%$
$127(60.0)$
$40 \%-59 \%$
$67(31.6)$
$20 \%-39 \%$
$18(8.5)$

Preoperative electrocardiogram

Atrial fibrillation or flutter

$1(0.5)$

Complete heart block/pacemaker

$1(0.5)$

Associated diseases

Hypertension

$29(13.6)$

Hyperlipidemia

$20(9.4)$

Severe chronic obstructive pulmonary disease

$1(0.5)$

Previous stroke or transient ischemic attack

$8(3.8)$

Diabetes mellitus

$2(0.9)$

Endocarditis

$15(7.1)$

Healed

$13(6.3)$

Active

$2(0.9)$

Pathology/pathophysiology

Mitral regurgitation

$4(1.9)$

AV lesion

Stenosis

$107(50.4)$

Insufficiency

77 (36.3)

Mixed lesion

$28(13.2)$

AV pathology

Bicuspid

Other congenital

$22(10.3)$

Prosthetic dysfunction

$10(4.7)$ 
TABLE 1. Continued

\begin{tabular}{lc}
\hline \multicolumn{1}{c}{ Variables } & Result \\
\hline Tricuspid calcific & $3(1.4)$ \\
Rheumatic & $6(2.8)$ \\
Miscellaneous & $19(9.0)$ \\
Operative data & \\
Aortic annulus diameter (mm mean \pm SD) & $26.2 \pm 6.1$ \\
Aortic annulus $>27$ mm & $120(56.6)$ \\
Aortic annular enlargement & $5(1.4)$ \\
Implantation technique & \\
$\quad$ Inclusion or subcoronary & $104(49.0)$ \\
$\quad$ Root replacement & $108(50.9)$ \\
Surgical reduction of the aortic root & \\
$\quad$ None & $90(42.7)$ \\
$\quad$ Aortic annulus & $61(28.9)$ \\
$\quad$ Sinotubular junction & $25(11.9)$ \\
$\quad$ Aortic annulus and sinotubular junction & $35(16.6)$ \\
Replacement of ascending aorta & $25(11.8)$ \\
Mitral valve repair & $4(1.9)$ \\
Crossclamp time, median min (IQR) & $123(114-133)$ \\
Cardiopulmonary bypass time, median min (IQR) & $141(130-153)$ \\
\hline
\end{tabular}

Data are presented as n (\%), unless otherwise indicated. $I Q R$, Interquartile range; $A V$, aortic valve; $N Y H A$, New York Heart Association; $S D$, standard deviation.

severe AI was considered an important adverse event, as well as pulmonary valve dysfunction (moderate or severe PI or peak systolic gradient $\geq 40 \mathrm{~mm}$ $\mathrm{Hg}$ ). Other outcomes of interest were thromboembolic events, endocarditis, myocardial infarction, and pacemaker implantation.

Baseline clinical and surgical characteristics were summarized using descriptive statistics. Continuous variables were summarized in terms of mean \pm standard deviation or median (IQR) as appropriate. Dichotomous and polytomous variables were summarized in terms of frequencies and proportions.

Mortality was estimated using the Kaplan-Meier method. Cumulative incidences of time-related outcomes other than mortality (reoperations, thromboembolic event, endocarditis, myocardial infarct, and pacemaker insertion) were calculated with mortality as a competing risk. Patients without an event of a particular type were censored at the end of their follow-up.

Repeated-measures regression models with auto-regressive correlation structure were used to estimate the probability odds of AI or PI or pulmonary stenosis over time, as well as the relationship between time since surgery and echocardiographic measurements such as aortic root diameter. Only data from echocardiograms obtained after the Ross procedure and before any valve reoperation were included in the repeated-measures analysis.

Cox regression models were used for risk factor analysis of specific subtypes of reoperations. Logistic regression models adjusted for repeated measures as described were used for risk factor analysis of longitudinal echocardiographic outcomes. Given the limited sample size available and the known risk factors for major outcomes of the Ross procedure, an a priori variable selection strategy was used. Factors considered included age, gender, time since surgery, aortic annulus diameter, and preoperative AI. All statistical analyses were performed using SAS v9.4 (SAS Institute Inc, Cary, NC)

\section{RESULTS \\ Mortality}

There was 1 operative death due to myocardial infarction and 15 late deaths; 3 were valve-related, 11 were noncardiac deaths, and 1 was of unknown cause. Table 2 shows cumulative deaths over the years; at 20 years, mortality was $10.8 \%$ (95\% confidence interval [CI], 6.5-17.8).

\section{Reoperations}

During a median follow-up of 18 years, 33 patients $(15.6 \%)$ have required cardiac reoperations: $30(14.2 \%)$ Ross-related and $3(1.4 \%)$ for coronary artery disease. Table 3 lists the Ross-related reoperations: 17 isolated pulmonary autograft reoperations, 6 pulmonary autograft combined with pulmonary valve homograft reoperation, and 7 pulmonary valve homograft reinterventions (1 surgical replacement and 6 transcatheter implantation of bioprosthetic valves into the disease pulmonary valve homograft). The pulmonary autograft was preserved in 6 patients $(26.1 \%)$ and replaced in 17 patients $(73.9 \%)$ as described in Table 3. Degeneration of the pulmonary autograft cusps precluded a satisfactory repair in these $17 \mathrm{pa}-$ tients. In addition, 3 patients with normally functioning Ross valves required coronary artery bypass graft. There was no operative mortality or any serious complication (stroke, myocardial infarction, or infection) among these

TABLE 2. Mortality rate and cumulative incidence of nondeath outcomes (percentage [ $95 \%$ confidence interval]) obtained using Kaplan-Meier estimates with death as a competing risk (for nondeath outcomes)

\begin{tabular}{|c|c|c|c|c|c|}
\hline Outcomes & $\frac{1 \mathrm{y}}{(95 \% \mathrm{CI})}$ & $\frac{5 y}{(95 \% \text { CI })}$ & $\frac{10 \mathrm{y}}{(95 \% \mathrm{CI})}$ & $\frac{15 \mathrm{y}}{(95 \% \mathrm{CI})}$ & $\frac{20 \mathrm{y}}{(95 \% \mathrm{CI})}$ \\
\hline Death & $0.5 \%(0.1-3.3)$ & $1.4 \%(0.5-4.3)$ & $2.4 \%(1.0-5.6)$ & $5.5 \%(3.1-9.6)$ & $10.8 \%(6.5-17.8)$ \\
\hline Any Ross-related reoperation & $1.4 \%(0.5-4.3)$ & $2.9 \%(1.3-6.2)$ & $5.8 \%(3.3-9.9)$ & $8.4 \%(5.3-13.2)$ & $16.8 \%(11.3-24.5)$ \\
\hline Death or any Ross-related reoperation & $1.9 \%(0.7-4.9)$ & $4.2 \%(2.2-8.0)$ & $8.1 \%(5.1-12.7)$ & $12.7 \%(8.8-18.1)$ & $26.0 \%(19.2-34.7)$ \\
\hline Pulmonary autograft reoperation & $1.4 \%(0.5-4.3)$ & $2.9 \%(1.3-6.2)$ & $4.8 \%(2.6-8.7)$ & $6.3 \%(3.7-10.7)$ & $11.5 \%(7.2-18.0)$ \\
\hline Pulmonary homograft reoperation & No event & No event & $1.9 \%(0.7-5.1)$ & $3.6 \%(1.7-7.4)$ & $8.2 \%(4.6-14.7)$ \\
\hline Thromboembolic event & No event & No event & No event & $1.1 \%(0.3-4.2)$ & $2.3 \%(0.7-7.8)$ \\
\hline Prosthetic valve endocarditis & No event & No event & $1.4 \%(0.5-4.4)$ & $2.4 \%(1.0-5.8)$ & $3.4 \%(1.5-7.7)$ \\
\hline Myocardial infarction & No event & No event & $1.0 \%(0.2-3.8)$ & $1.0 \%(0.2-3.8)$ & $1.0 \%(0.2-3.8)$ \\
\hline Pacemaker insertion & No event & No event & No event & $0.5 \%(0.1-3.6)$ & $1.5 \%(0.3-6.1)$ \\
\hline
\end{tabular}

CI, Confidence interval. 
TABLE 3. List of Ross-related reoperations

\begin{tabular}{|c|c|c|c|c|}
\hline Patient & $\begin{array}{l}\text { Preoperative } \\
\text { AV lesion }\end{array}$ & $\begin{array}{c}\text { Ross } \\
\text { technique }\end{array}$ & Time since surgery & Reoperation and indication for surgery \\
\hline 1 & AI & $\mathrm{RR}$ & $11 \mathrm{~d}$ & AVR for moderate AI \\
\hline 2 & AI & $\mathrm{SC}$ & $6 \mathrm{mo}$ & AVR for severe AI \\
\hline 3 & AI & $\mathrm{RR}$ & $9 \mathrm{mo}$ & Repair of subaortic false aneurysm \\
\hline 4 & AS & RR & $17 \mathrm{mo}$ & Repair of subaortic false aneurysm \\
\hline 5 & AI & $\mathrm{SC}$ & $31 \mathrm{mo}$ & AVR for moderate to severe AI \\
\hline 6 & AI & SC & $50 \mathrm{mo}$ & AVR for severe AI \\
\hline 7 & AS & SC & $61 \mathrm{mo}$ & PVR for PVH dysfunction \\
\hline 8 & AS & $\mathrm{RR}$ & $95 \mathrm{mo}$ & Transcatheter PVR for PVH dysfunction \\
\hline 9 & AI & $\mathrm{RR}$ & $107 \mathrm{mo}$ & AVR for severe AI \\
\hline 10 & AI & $\mathrm{SC}$ & $108 \mathrm{mo}$ & AVR for moderate AI + PVR for endocarditis of PVH \\
\hline 11 & AS/AI & SC & $109 \mathrm{mo}$ & AVR for severe AI \\
\hline 12 & AI & SC & $115 \mathrm{mo}$ & AVR for moderate AI + PVR for PVH dysfunction \\
\hline 13 & AI & SC & $135 \mathrm{mo}$ & $\mathrm{AV}$ repair for $\mathrm{AI}+\mathrm{TV}$ repair for TR + PVR for endocarditis of PVH \\
\hline 14 & AI & $\mathrm{RR}$ & $136 \mathrm{mo}$ & AVR for severe AI \\
\hline 15 & AS & $\mathrm{RR}$ & $143 \mathrm{mo}$ & Transcatheter PVR for PVH dysfunction \\
\hline 16 & AS & $\mathrm{SC}$ & $157 \mathrm{mo}$ & AVS for aortic root aneurysm \\
\hline 17 & AS & $\mathrm{RR}$ & $172 \mathrm{mo}$ & Transcatheter PVR for PVH dysfunction \\
\hline 18 & AI & $\mathrm{SC}$ & $187 \mathrm{mo}$ & AVS for aortic root aneurysm \\
\hline 19 & AI & $\mathrm{SC}$ & $187 \mathrm{mo}$ & AVR for severe AI \\
\hline 20 & AI & $\mathrm{RR}$ & $190 \mathrm{mo}$ & AVS for ascending aortic aneurysm \\
\hline 21 & AS & SC & $197 \mathrm{mo}$ & Transcatheter PVR for pulmonary \\
\hline 22 & AS/AI & $\mathrm{RR}$ & $203 \mathrm{mo}$ & AVR for severe AI \\
\hline 23 & AI & $\mathrm{RR}$ & $221 \mathrm{mo}$ & Transcatheter PVR for PVH dysfunction \\
\hline 24 & AS & SC & $232 \mathrm{mo}$ & AVR for moderate $\mathrm{AI}+\mathrm{PVR}$ for $\mathrm{PVH}$ endocarditis \\
\hline 25 & AI & $\mathrm{RR}$ & $237 \mathrm{mo}$ & AVR for severe AI \\
\hline 26 & AI & SC & $238 \mathrm{mo}$ & Transcatheter PVR for PVH dysfunction \\
\hline 27 & AI & $\mathrm{SC}$ & $241 \mathrm{mo}$ & AVR for severe AI + PVR for PVH dysfunction \\
\hline 28 & AI & $\mathrm{RR}$ & $266 \mathrm{mo}$ & AVR for severe AI \\
\hline 29 & AS & $\mathrm{RR}$ & 270 mo AVR for severe AI & \\
\hline 30 & AS & $\mathrm{RR}$ & $270 \mathrm{mo}$ & $\begin{array}{l}\text { AVR for moderate AI, MVR for MS and MR, TV repair for TR, PVR for } \\
\text { PVH dysfunction }\end{array}$ \\
\hline
\end{tabular}

$A V$, Aortic valve; $A I$, aortic insufficiency; $R R$, root replacement; $A V R$, aortic valve replacement; $S C$, subcoronary implantation; $A S$, aortic stenosis; $P V R$, pulmonary valve replacement; $P V H$, pulmonary valve homograft; $T V$, tricuspid valve; $T R$, tricuspid regurgitation; $A V S$, aortic valve sparing; $M V R$, mitral valve replacement; $M S$, mitral stenosis; $M R$, mitral regurgitation.

33 patients who underwent reoperations. Figure 1 shows the cumulative incidence of Ross-related reoperation or reintervention: At 20 years, it was $16.8 \%$ (95\% CI, 11.3-24.5). Table 2 shows the cumulative incidence of Ross-related reinterventions (surgical and transcatheter) at various time intervals. Table 4 shows a risk-factor analysis of factors associated with reoperation on the pulmonary autograft. Older age and larger aortic annulus size were associated with increased risk of pulmonary autograft reoperation in multivariable models. It is noteworthy that the technique of implantation of the pulmonary autograft was not associated with odds of reoperation on the pulmonary autograft (hazard ratio, 1.02; 95\% CI, 0.41-2.56, $P=.97$ for root replacement vs subcoronary or aortic root inclusion). In a separate analysis, the only risk factor associated with pulmonary homograft reoperation was female gender (hazard ratio, 12.86; 95\% CI, 1.47-115.85; $P=.021$ ).

\section{Aortic Insufficiency}

AI was the only mode of failure of the pulmonary autograft. Figure 2 shows the probability of developing moderate or severe AI over time; at 20 years it was $13.0 \%(95 \% \mathrm{CI}$, 8.0-20.3). Table 5 shows the probability of developing moderate or severe AI at various time intervals. Table 6 shows 


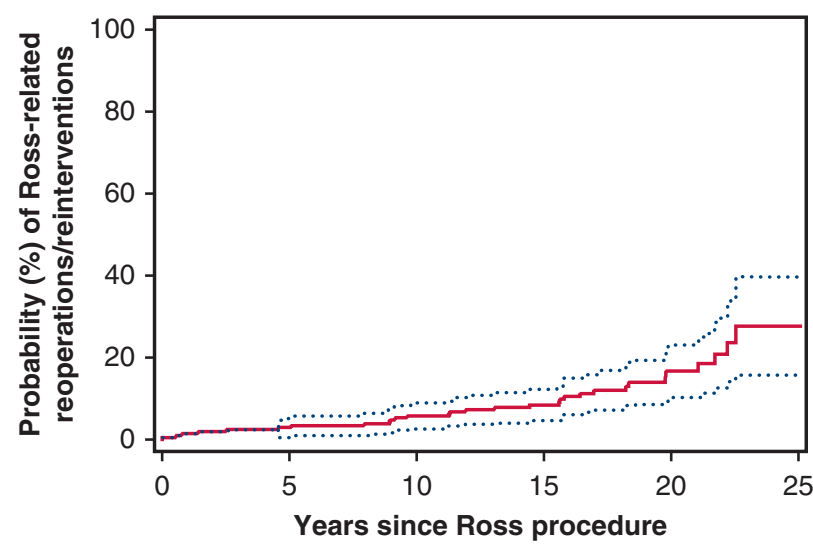

At-risk: $212 \quad 201 \quad 192 \quad 144 \quad 58 \quad 1$

FIGURE 1. Cumulative incidence of Ross-related reoperations or reinterventions over time. Cumulative incidence of Ross-related reoperations or reintervention was calculated with death as a competing risk.

the results of multivariable analyses to identify preoperative factors associated with the development of postoperative AI. Factors associated with increased odds of moderate or severe AI included older age at operation, male gender, presence of preoperative $\mathrm{AI}$, and time since the operation.

\section{Pulmonary Valve Homograft Dysfunction}

Figure 3 shows the probability of pulmonary valve homograft dysfunction over time; at 20 years it was $19.7 \%(95 \%$ CI, 13.9-27.2). Table 5 shows the probability of pulmonary homograft dysfunction at various time intervals.

\section{Dilatation of the Aortic Root}

The maximal diameter of the aortic root or ascending aorta diameter was $45 \mathrm{~mm}$ or greater in 17 patients, but the diameter exceeded $50 \mathrm{~mm}$ in only 4 patients, and they received reoperations with preservation of the pulmonary autograft (Table 3). Figure 4 shows the increase in diameter over time according to the operative technique of implantation

TABLE 4. Hazard ratios ( $95 \%$ confidence interval) for factors associated with pulmonary autograft reoperation only: Multivariable Cox regression models were used to estimate the hazard ratios of pulmonary autograft reoperation versus age, sex, preoperative aortic valve regurgitation, and aortic annulus size

\begin{tabular}{lcc}
\hline & $\begin{array}{c}\text { Multivariable } \\
\text { HR (95\% CI) }\end{array}$ & $\boldsymbol{P}$ value \\
\hline Age (1-y increment) & $1.092(1.017-1.172)$ & .015 \\
Sex (ref = male) & $0.609(0.071-5.193)$ & .65 \\
$\begin{array}{l}\text { Preoperative AV regurgitation } \\
\quad(\text { vs stenosis) }\end{array}$ & $1.381(0.340-5.603)$ & .65 \\
$\begin{array}{l}\text { Aortic annulus size (1-mm } \\
\quad \text { increment) }\end{array}$ & $1.531(1.257-1.865)$ & $<.001$ \\
\hline$H R$, Hazard ratio; $C I$, confidence interval; $A V$, aortic valve. &
\end{tabular}

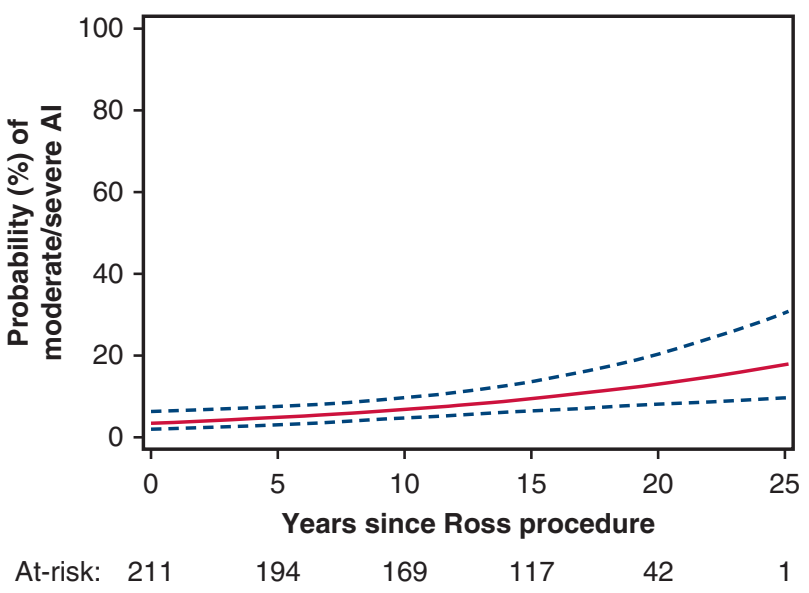

FIGURE 2. Predicted probability (solid line) of moderate or severe aortic insufficiency with $95 \%$ confidence limits (dashed line) over time. AI, Aortic insufficiency.

of the pulmonary autograft. The slope of the change in aortic root or ascending aorta diameter over time was estimated using repeated-measures generalized linear models. The slope estimates were $0.358(0.229-0.487) \mathrm{mm} / \mathrm{year}(P<.001)$ for the root replacement group and $0.211(0.073-0.349) \mathrm{mm} / \mathrm{y}$ $(P<.001)$ for the subcoronary implantation group. The difference in the increase over time across the 2 groups was not statistically significant $(P=.12)$.

\section{Other Adverse Events}

Table 2 shows the cumulative incidence of other morbid events over time. Infective endocarditis of the failing pulmonary valve homograft developed in 7 patients. All 7 patients required reintervention, but in only 2 during the active phase of the infection.

\section{DISCUSSION}

There is no perfect AV substitute, and AVR to treat AV disease is a palliative procedure. Matching the patient to the type of heart valve substitute is particularly difficult in children and young adults. Both bioprosthetic and mechanical valves are associated with high rates of valve-related complications. In a large population-based study of patients in California, mortality at 15 years after bioprosthetic and mechanical AVR in patients aged 45 to 54 years was $30.6 \%$ and $26.4 \%$, respectively. ${ }^{5}$ Cumulative incidence of prosthesis-related complications, including stroke, bleeding, and reoperation, was high. ${ }^{5}$

Age remains the most important determinant of bioprosthetic heart valve durability, and more than $50 \%$ of patients require redo AVR by 15 years after surgery. ${ }^{6}$ The use of bioprosthetic heart valves has increased dramatically in patients aged 18 to 50 years. ${ }^{7}$ In a recent study based on statewide databases from California and New York, the proportion of patients who received a bioprosthetic valve for 
TABLE 5. Point estimates of the probability of echocardiographic outcomes over time since Ross procedure: Repeated-measures generalized linear models with autoregressive correlation structures were used to derive point estimates of the probability of echocardiographic outcomes over time

\begin{tabular}{|c|c|c|c|c|c|}
\hline Outcomes & $\frac{1 \mathbf{y}}{(95 \% \mathrm{CI})}$ & $\frac{5 y}{(95 \% C I)}$ & $\frac{10 y}{(95 \% \mathrm{CI})}$ & $\frac{15 y}{(95 \% \mathrm{CI})}$ & $\frac{20 \mathrm{y}}{(95 \% \mathrm{CI})}$ \\
\hline AI moderate or greater & $3.6 \%(2.0-6.4)$ & $4.8 \%(3.0-7.5)$ & $6.7 \%(4.7-9.6)$ & $9.4 \%(6.4-13.4)$ & $13.0 \%(8.0-20.3)$ \\
\hline $\begin{array}{l}\text { PVH insufficiency moderate } \\
\text { or greater }\end{array}$ & $4.5 \%(2.4-8.5)$ & $5.8 \%(3.5-9.6)$ & $8.0 \%(5.4-11.6)$ & $10.8 \%(7.6-15.1)$ & $14.4 \%(9.6-21.1)$ \\
\hline $\begin{array}{l}\text { PVH peak gradient } \geq 40 \mathrm{~mm} \\
\quad \mathrm{Hg}\end{array}$ & $1.2 \%(0.4-3.6)$ & $1.9 \%(0.8-4.4)$ & $3.2 \%(1.7-5.9)$ & $5.4 \%(3.2-8.8)$ & $8.9 \%(5.1-15.0)$ \\
\hline $\begin{array}{l}\text { PVH peak gradient } \geq 40 \text { or } \\
\text { PI } \geq 3\end{array}$ & $6.2 \%(3.6-10.4)$ & $8.0 \%(5.2-12.0)$ & $10.9 \%(7.9-14.9)$ & $14.7 \%(10.9-19.6)$ & $19.7 \%(13.9-27.2)$ \\
\hline
\end{tabular}

$C I$, Confidence interval; $A I$, aortic insufficiency; $P V H$, pulmonary valve homograft; $P I$, pulmonary insufficiency.

AVR increased from $14.3 \%$ in 1997 to $47.1 \%$ in $2006 .^{7}$ No difference was observed in survival up to 15 years after isolated AVR with bioprosthetic compared with mechanical valves. ${ }^{7}$ Of note, the probability of reoperation on patients with bioprosthetic valve was only $24.5 \%$ at 15 years, much lower than in other reports ${ }^{6,8,9}$ and likely underestimated.

Mechanical valves are more durable than bioprosthetic heart valves, but in addition to anticoagulation-related complications, pannus formation with consequent prosthetic valve stenosis is likely underdiagnosed after AVR. For these reasons, we continue to believe that the Ross procedure remains the best operation to treat aortic stenosis in young adults. ${ }^{1}$ This may not be the case for a young patient with AI, particularly if the aortic annulus is dilated. ${ }^{10}$ In a previous report on the Ross procedure, we found that preoperative AI, dilated aortic annulus $(\geq 28 \mathrm{~mm})$, and mismatch in the diameters of the aortic and pulmonary annuluses $3 \mathrm{~mm}$ or greater were associated with risk of developing postoperative AI. ${ }^{10}$ Because of those findings, we have been reluctant to offer the Ross procedure to patients with AI and dilated aortic annulus except in women of

TABLE 6. Multivariable odds ratios ( $95 \%$ confidence interval) of moderate or severe aortic insufficiency: Repeated-measures logistic regression with autoregressive correlation structure was used to derive odds ratio of the occurrence of moderate or severe aortic insufficiency versus age, sex, preoperative aortic insufficiency, and aortic annulus size

\begin{tabular}{llc}
\hline & $\begin{array}{c}\text { Multivariable } \\
\text { OR }(\mathbf{9 5} \% \mathbf{C I})\end{array}$ & $\boldsymbol{P}$ value \\
\hline Age (1-y increment) & $1.047(1.004-1.093)$ & .033 \\
Male gender (vs female) & $2.269(0.987-5.213)$ & .054 \\
Preoperative AI (vs stenosis) & $5.067(1.498-17.132)$ & .009 \\
$\begin{array}{l}\text { Aortic annulus size (1-mm } \\
\quad \text { increment) }\end{array}$ & $0.945(0.881-1.013)$ & .11 \\
Time since Ross procedure (y) & $1.071(1.022-1.123)$ & .004 \\
\hline
\end{tabular}

$O R$, Odds ratio; $C I$, confidence interval; $A I$, aortic insufficiency. childbearing age who have limited options. The probability of reoperation in these patients is high and may not be different than that with commercially available bioprosthetic heart valves. It is noteworthy to mention that the technique of implantation had no effect on the development of $\mathrm{AI}$ in our patients.

The median age of our patients was 34 years, and the series contains no patient younger than 16 years or older than 63 years, and the observations made are applicable only to this age group. In a previous publication on this same cohort, we found that late survival was similar to that of the general population, ${ }^{10}$ but this may be a reflection of the clinical profile of our patients rather than the effect of the Ross procedure. When we compared patients with AVR with a mechanical valve with those undergoing the Ross procedure using a propensity score analysis, longterm survival was similar. ${ }^{11}$ The cumulative incidence of Ross-related reoperations in this cohort was $16.8 \%$ at 20 years, and this is certainly superior to AVR with bioprosthetic valves or AV homograft in this age group. ${ }^{6-9}$ It is noteworthy that no patient died or had a serious adverse event after a Ross-related reoperation.

We found that the technique of implantation of the pulmonary autograft was not associated with adverse outcomes. Implantation of the pulmonary autograft in the subcoronary position is more complex than aortic root replacement because it requires a greater knowledge of the functional anatomy of the semilunar valves and the surgeon's ability to match the geometry of the pulmonary valve cusps to a frequently abnormal aortic root. However, even when the aortic root replacement technique is used, the surgeon must apply the principles of functional anatomy to ensure that the diameters of the native aortic annulus and sinotubular junction match those of the pulmonary autograft and the anatomy of the transplanted pulmonary root is not altered. ${ }^{3}$ Furthermore, the pulmonary-ventricular junction (pulmonary annulus) must be placed at the same level of or immediately beneath the aorto-ventricular junction and no foreign material used in this anastomosis. Regardless 


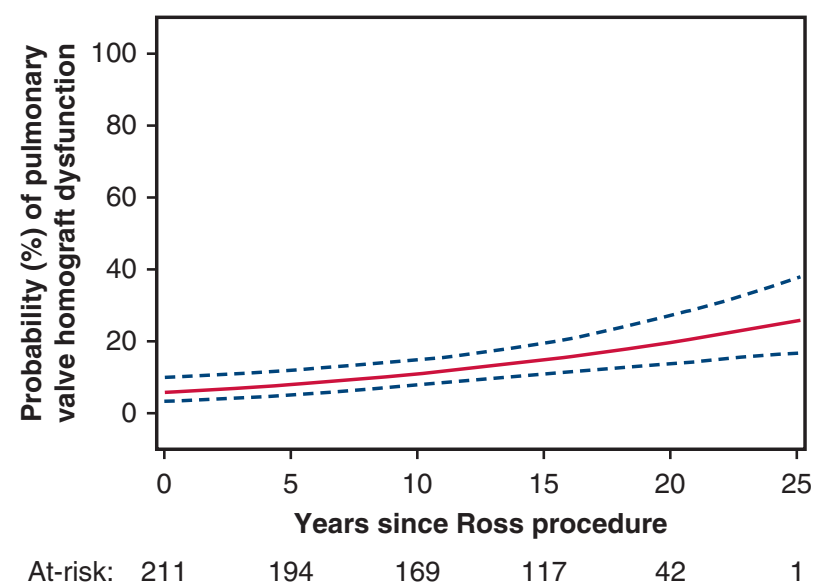

FIGURE 3. Predicted probability (solid line) of pulmonary valve homograft dysfunction with $95 \%$ confidence limits (dashed line). Pulmonary valve homograft dysfunction was defined as pulmonary regurgitation grade 3 or greater or peak systolic gradient $40 \mathrm{~mm} \mathrm{Hg}$ or greater measured by echocardiography.

of the technique of implantation of the pulmonary autograft, it seems that after a long period of observation, the Ross procedure may eventually fail. In this present study, we observed a steady increase in the rate of AI after the Ross procedure even in patients with preoperative aortic stenosis and entirely normal neo-AV function during the first decade after surgery. The expectation that the pulmonary autograft would adapt itself to the systemic circulation and perhaps a valve for life may be unrealistic because in addition to technical problems in transferring the pulmonary valve to the aortic position, severance of the pulmonary root from its native location affects its blood supply, innervation, and other anatomic elements essential for a heart valve to remain "a living structure" and last a lifetime. We found that older age adversely affected the durability of the

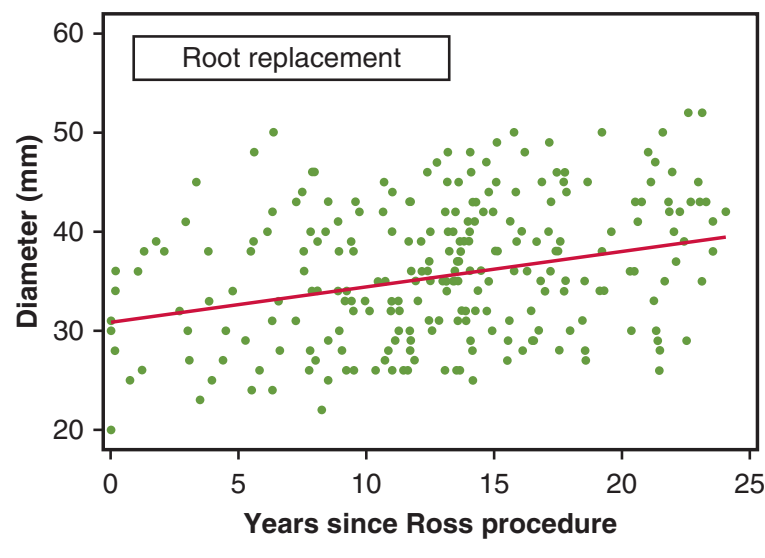

pulmonary autograft, suggesting that aging may play a role in adaptation of the pulmonary valve and raising the issue of appropriateness of the Ross procedure in older patients.

The long-term results of the Ross procedure have not been consistent in all reports: Some authors report results similar to ours, ${ }^{12,13}$ whereas others showed earlier and higher failure rates. ${ }^{4,14}$ In a recent article by Sievers and colleagues $^{12}$ on a cohort of 622 patients with a mean age of 44.7 years who received the Ross procedure exclusively using the techniques of subcoronary implantation and aortic root inclusion, the freedom from Ross-related valve reoperation at 20 years was $85.9 \% .{ }^{12}$ In contrast, Martin and colleagues ${ }^{14}$ reported on a cohort of 310 patients with a mean age of 40.8 years who received the Ross procedure using both implantation techniques, and the freedom from Rossrelated reoperation at 20 years was $70.1 \%$. However, Martin and colleagues' results during the first decade were similar to those of Sievers and colleagues ${ }^{12}$ and ours, suggesting that other factors played a role in late failures. Bicuspid AV disease is the principal indication for AVR in young adults in the Western world, and the various phenotypes of this entity play a role in the durability of the Ross procedure. In Sievers and colleagues' series, approximately $50 \%$ of patients with preoperative AI developed postoperative AI by 20 years. ${ }^{12}$ We believe that some genetic abnormality in the pulmonary valve of patients with bicuspid AV and AI causes premature failure of the pulmonary autograft. ${ }^{15}$ In our study, we found that advancing age, male gender, preoperative AI, duration of follow-up, and possibly larger aortic annulus were associated with the development of AI after the Ross procedure (Video 1).

\section{Study Limitations}

Our study has several limitations. All operations were performed by 1 surgeon, and the results may not be

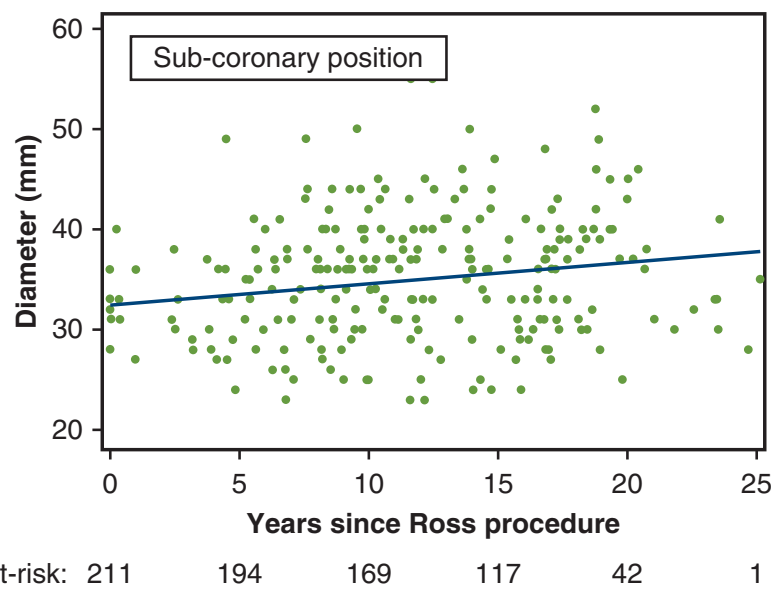

FIGURE 4. Maximum diameter of the aortic root or proximal ascending aorta over time. Maximum diameter of the aortic root or proximal ascending aorta over time after the Ross procedure in patients who underwent aortic root replacement $(\mathrm{N}=108$, left $)$ or subcoronary implantation $(\mathrm{N}=104$, right $)$. 


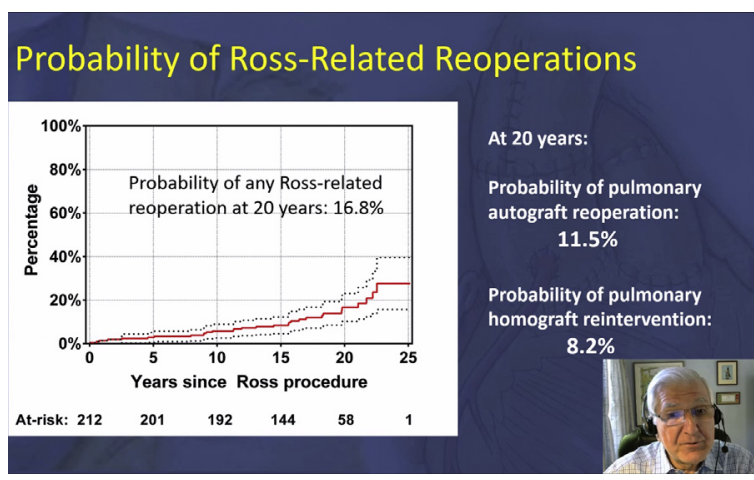

VIDEO 1. Tirone David presents a series of slides describing his experience with the Ross procedure and discusses 2 other recent articles on longterm results of this operation. Video available at: https://www.jtcvs.org/ article/S0022-5223(18)31782-3/fulltext.

generalizable. The sample size was small with consequent limited reliability of the risk adjustment given the small number of adverse events available for analysis. In addition, some factors had a wide CI, suggesting potentially limited reliability.

\section{CONCLUSIONS}

On the basis of the current evidence, the Ross procedure should be part of the surgical armamentarium to treat aortic stenosis in young adults. The issue of preoperative AI, aortic annular dilatation, various phenotypes of bicuspid $\mathrm{AV}$, and the techniques of implantation of the pulmonary autograft need further investigation of their effects on late outcomes. Finally, this is a complex operation and should be performed only by surgeons with experience in $\mathrm{AV}$ repair who have a reasonable volume of $\mathrm{AV}$ operations each year and have a good understanding of functional anatomy of the semilunar valves.

\section{Conflict of Interest Statement}

Authors have nothing to disclose with regard to commercial support.

\section{References}

1. Ouzounian M, Mazine A, David TE. The Ross procedure is the best operation to treat aortic stenosis in young and middle-aged adults. J Thorac Cardiovasc Surg. 2017; 154:778-82.

2. Stelzer P, Jones DJ, Elkins RC. Aortic root replacement with pulmonary autograft. Circulation. 1989;80(suppl III):III209-13.

3. David TE, Omran A, Webb G, Rakowski H, Armstrong S, Sun Z. Geometric mismatch the aortic and pulmonary roots causes aortic insufficiency after the Ross procedure. J Thorac Cardiovasc Surg. 1996;112:1231-9.

4. Mokhles MM, Rizopoulos D, Andrinopoulou ER, Bekkers JA, RoosHesselink JW, Lesaffre E, et al. Autograft and pulmonary allograft performance in the second post-operative decade after the Ross procedure: insights from the Rotterdam prospective cohort study. Eur Heart J. 2012;33:2213-24.

5. Goldstone AB, Chiu P, Baiocchi M, Lingala B, Patrick WL, Fischbein MP, et al. Mechanical or biologic prostheses for aortic-valve and mitral-valve replacement. N Engl J Med. 2017;377:1847-57.

6. Une D, Ruel M, David TE. Twenty-year durability of the aortic Hancock II bioprosthesis in young patients: is it durable enough? Eur J Cardiothorac Surg. 2014;46:825-30.

7. Schnittman SR, Adams DH, Itagaki S, Toyoda N, Egorova NN, Chikwee J. Bioprosthetic aortic valve replacement: revisiting prosthesis choice in patients younger than 50 years old. J Thorac Cardiovasc Surg. 2018;155:539-47.

8. Bourguignon T, Bouquiaux-Stablo AL, Candolfi P, Mirza A, Loardi C, May MA, et al. Very long-term outcomes of the Carpentier-Edwards Perimount valve in aortic position. Ann Thorac Surg. 2015;99:831-7.

9. Smedira NV, Blackstone EH, Roselli ER, Laffey CC, Cosgrove DM. Are allograft the biologic valve of choice for aortic valve replacement in nonelderly patients? Comparison of explantation for structure valve deterioration of allograft and pericardial prostheses. J Thorac Cardiovasc Surg. 2006;131:558-64.

10. David TE, David C, Woo A, Manlhiot C. The Ross procedure: outcomes at 20 years. J Thorac Cardiovasc Surg. 2014;147:85-93.

11. Mazine A, David TE, Rao V, Hickey EJ, Christie S, Manlhiot C, et al. Long-term outcomes of the Ross procedure versus mechanical aortic valve replacement: propensity-matched cohort study. Circulation. 2016;134:576-85.

12. Sievers H-H, Stierlel U, Petersen M, Koltz S, Richardt D, Diwoky M, et al. Valve performance classification 1 in 630 subcoronary Ross patients over 22 years. J Thorac Cardiovasc Surg. 2018;156:79-86.e2.

13. Skillington PD, Mokhles M, Takkenberg JM, Larobina M, O'Keefe M, Wynne R, et al. The Ross procedure using autologous support of the pulmonary autograft: techniques and late results. J Thorac Cardiovasc Surg. 2017; 149(Suppl):S46-52.

14. Martin E, Mohammadi S, Jacques F, Kalavrouziotis D, Voisine P, Doyle D, et al. Clinical outcomes following the Ross procedure in adults. J Am Coll Cardiol. 2017;70:1890-9.

15. de Sa M, Moshkovitz Y, Butany J, David TE. Histologic abnormalities of the aorta and pulmonary trunk in patients with aortic valve disease: clinical relevance to the Ross procedure. J Thorac Cardiovasc Surg. 1999;118:588-94.

Key Words: aortic valve replacement, Ross procedure 